\title{
DELIBERATE HYPOTENSION FOR SPINAL FUSION: PROSPECTIVE RANDOMIZED STUDY WITH EVOKED POTENTIAL MONITORING
}

\author{
Betty L. Grundy, Clyde L. Nash, JR., and Richard H. Brown
}

\begin{abstract}
Twenty-four patients requiring spinal fusion with Harrington rod instrumentation were studied prospectively to determine the effects of moderate hypotension on blood loss, operating conditions, operating time and spinal cord function. Hypotension reduced blood loss and improved operating conditions but did not shorten operating time. Five patients had alterations in somatosensory cortical evoked potentials after straightening of the spine that prompted us to reverse hypotension (when present) and haemodilution, and then to do wake-up tests. All wake-up tests were normal and all evoked potential alterations resolved during operation. Hypotension seems unlikely to increase the risk of neurological damage if spinal cord function is monitored. Our findings suggest that patients subjected to spinal fusion need not be awakened during operation for testing of cord function provided somatosensory evoked potentials are monitored and remain stable.
\end{abstract}

Key Words: Surgery, spinal fusion; ANaesthetic Techniques, induced hypotension; MONITORING, cortical evoked potentials.

IN PATIENTS with scoliosis, operations on the spine are associated with a small but definite risk of damage to the spinal cord and consequent paraplegia. ${ }^{1}$ The mechanism of cord injury, though not fully understood, is thought to be primarily ischaemic. ${ }^{2,3}$ Deliberate hypotension has been advocated as a means of reducing blood loss and improving operating conditions during fusion of the spine, ${ }^{4-6}$ but studies in animals have shown that hypotension and direct pressure on the spinal cord are additive in producing neurological impairment. ${ }^{7}$

Spinal cord function can be monitored during operation by awakening the patient to test motor function in the lower extremities ${ }^{8-10}$ or by measuring transmission of sensory impulses through the spinal cord with evoked potential recordings. ${ }^{11-15}$ Deteriorating cord function can

Betty L. Grundy, M.D., Assistant Professor of Anesthesiology and Neurosurgery, University of Pittsburgh; Clyde L. Nash, Jr., M.D., Associate Professor of Orthopedics, Case Western Reserve University; Richard H. Brown, Ph.D., Assistant Professor of Orthopedic Engineering, Case Western Reserve University.

This work was done at Case Western Reserve University and University Hospitals of Cleveland. It was supported by Grants Number GM 26264, GM 27942 and GM 19599 from the National Institute of General Medical Sciences and by Grant 267 from the Orthopedic Research and Education Foundation. This work was presented in part to the American Society of Anesthesiologists in 1979. then be treated during operation by raising arterial pressure, reducing distraction of the spine or, if need be, removing Harrington rods.

We prospectively examined the use of modest hypotension during spinal fusion with Harrington rod instrumentation to determine whether hypotension reduced blood loss, improved operating conditions, reduced operating time or impaired spinal cord function. This study was approved by the Institutional Review Board, University Hospitals of Cleveland.

\section{METHODS}

\section{Subjects}

We studied twenty-two females and two males, thirteen to twenty-four years of age, who required spinal fusion for scoliosis (Table I). All were ASA status II and were medically acceptable candidates for deliberately induced hypotension. None had neurological deficits. We assigned patients randomly to the hypotensive group (Group I) or to the nonhypotensive group (Group II) by drawing lots on the morning of operation. All patients were cared for by the same surgeon (CLN) and anaesthetist (BLG).

\section{Anaesthesia}

Subjects were premedicated intramuscularly with morphine $0.075 \mathrm{mg} \cdot \mathrm{kg}^{-1}$ and secobarbitone $1.5 \mathrm{mg} \cdot \mathrm{kg}^{-1}$. After baseline somatosensory cortical evoked potential (SCEP) recording we

Can. Anaesth. Soc. J., vol. 29, no. 5, September 1982 
TABLE I

Preoperative Characteristics of Patient Groups

\begin{tabular}{|c|c|c|c|}
\hline & $\begin{array}{c}\text { Group ! } \\
\text { (Hypotension) }\end{array}$ & $\begin{array}{c}\text { Group II } \\
\text { (No Hypotension) }\end{array}$ & $\mathrm{p}^{\dagger}$ \\
\hline $\begin{array}{l}\text { Number of Patients } \\
\text { females } \\
\text { males } \\
\text { Age }(\mathrm{yr})^{*} \\
\text { Weight }(\mathrm{kg})^{*} \\
\text { Hacmatocrit }(\%)^{*}\end{array}$ & $\begin{array}{l}13 \\
13 \\
0 \\
16.9 \pm 3.7 \\
50.9 \pm 7.4 \\
38.4 \pm 2.7\end{array}$ & $\begin{array}{l}11 \\
9 \\
2 \\
17.6 \pm 3.8 \\
52.4 \pm 7.7 \\
39.5 \pm 3.0\end{array}$ & $\begin{array}{l}\text { NSt } \\
\text { NS } \\
\text { NS }\end{array}$ \\
\hline $\begin{array}{l}\text { Baseline arterial pressure } \\
\text { systolic* } \\
\text { mean* }\end{array}$ & $\begin{array}{r}107 \pm 8.9 \\
80 \pm 5.6\end{array}$ & $\begin{array}{r}113 \pm 11.5 \\
84 \pm 9.1\end{array}$ & $\begin{array}{l}\text { NS } \\
\text { NS }\end{array}$ \\
\hline
\end{tabular}

* Mean \pm standard deviation.

tGroup I vs. Group II, Student's t test for unpaired data.

†NS = not significant at .05 level.

The groups are similar except that the only males were in group II. (Eighty percent of idiopathic adolescent scoliosis occurs in females. ${ }^{2}$ )

gave atropine $0.01 \mathrm{mg} \cdot \mathrm{kg}^{-1}$ intravenously and induced anaesthesia with morphine and thiopentone, using pancuronium $0.1 \mathrm{mg} \cdot \mathrm{kg}^{-1}$ for muscle relaxation. Nitrous oxide 60 to 70 per cent with oxygen and incremental doses of thiopentone, morphine, fentanyl and pancuronium served to maintain anaesthesia. A four-poster frame ${ }^{16}$ supported patients in the prone position. To prevent inadvertent hypothermia we wrapped extremities and used warming lamps until sterile drapes were in place. Two hundred to $400 \mathrm{ml}$ dilute epinephrine $(1: 500,000)$ were injected subcutaneously before incision to minimize blood loss. Dextrose five per cent in lactated Ringer's solution was infused at an initial rate of six to eight $\mathrm{ml} \cdot \mathrm{kg}^{-1} / \mathrm{hr}$ and thereafter as indicated clinically. We withheld transfusion until wound closure so long as monitored parameters were within acceptable limits and haematocrit was greater than 25 per cent. During surgical closure and early recovery packed red blood cells and whole blood were given to replace intraoperative and projected early postoperative blood loss, aiming for haematocrits near 35 per cent. We reversed muscle relaxants in the operating room, awakening patients rapidly to facilitate clinical neurological assessment.

\section{Monitoring}

Electrocardiogram, temperature and haemoglobin oxygen saturation (Hewlett Packard ear oximeter)* were recorded continuously. Arterial blood pressure was monitored noninvasively at two minute intervals using a Roche Arterio-

*Hewlett Packard, Andover, Massachusetts 01810. sonde** until insertion of a radial artery catheter for continuous monitoring of arterial blood pressure was accomplished under general anaesthesia. Arterial blood gas tensions, haematocrit, central venous pressure and urine output were measured every half hour. To estimate blood loss, we added the weight of blood on sponges and the volume of blood in suction, subtracted the volume of irrigating fluids and one-third the volume of epinephrine solution injected and then added 20 per cent to cover unmeasured loss.

\section{Induced Hypotension}

Either hypotension or sham hypotension was induced before decortication of the bone and maintained until retractors were removed and fascial closure begun, unless SCEP changes indicated earlier restoration of normotension. Patients in the hypotensive group (Group 1) received nitroprusside up to $10 \mu \mathrm{g} \cdot \mathrm{kg}^{-1} \cdot \min$. $^{-1}$ We added propranolol or trimethaphan or both as necessary to keep systolic arterial blood pressure between 80 and 90 torr (10.6-12.0 kPa). Patients in Group II (no hypotension) received a sham nitroprusside infusion, covered with foil and frequently adjusted but free of drug.

We averaged arterial blood pressures during specific time periods for each patient, then compared average mean and systolic intraarterial blood pressures during actual or sham induced hypotension with average mean and systolic arterial blood pressures obtained noninvasively during baseline SCEP recording.

**Roche Medical Electronics, Cranbury, New Jersey 08512 . 
TABLE II

Stimulation and Recording Parameters for SCEP

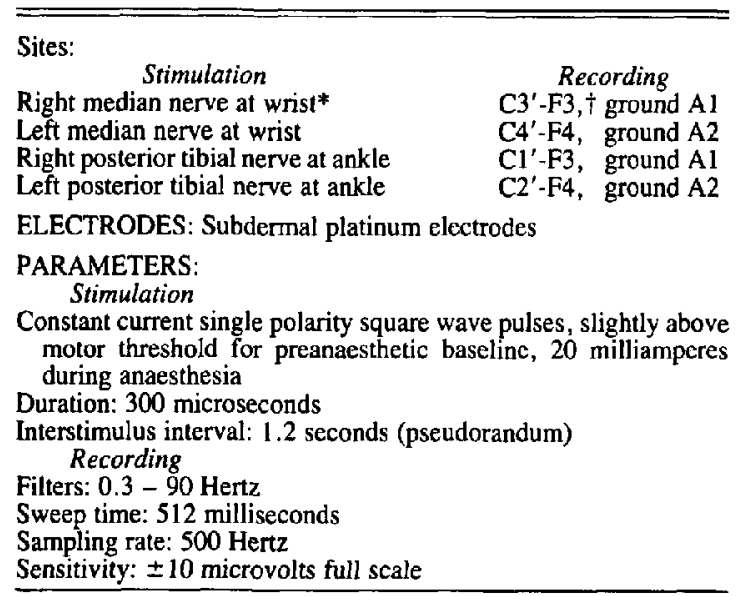

*Electrode pair, three centimeters apart, cathode proximal.

†Letters and numbers refer to the International Ten Twenty System ${ }^{17}$ for designating electrode positions. $\mathrm{Cl}^{\prime}, \mathrm{C2}^{\prime}, \mathrm{C}^{\prime}$ and $\mathrm{C}^{\prime}$ are two centimeters behind $\mathrm{C} 1, \mathrm{C} 2, \mathrm{C} 3$ and $\mathrm{C} 4$ respectively.

\section{Surgeon's Assessment}

The surgeon was not told whether patients were in Group I or Group II until after operation, when he and his first assistant separately completed questionnaires indicating their estimates of blood loss during operation and stating whether they thought the patient had been hypotensive. Until these questionnaires were completed, the surgeon received no information about blood loss, administration of blood or fluids or any monitored physiological parameters. He was, of course, fully aware of all details of the protocol. He assisted with wake-up tests and knew that hypotension, if present, would have been reversed before these were done. The surgeon equated his perception of induced hypotension with improved operating conditions.

\section{Somatosensory Cortical Evoked Potentials (SCEP)}

Evoked potentials were monitored using a system developed by one of the authors (RHB) for recording SCEP in the operating room. ${ }^{15}$ Each full set of SCEP records included sixteen waveforms: three averaged responses to stimulation of each extremity and background averages without somatosensory stimulation from each set of recording electrodes. Stimulation and recording parameters are listed in Table II. A representative waveform is shown in Figure 1.

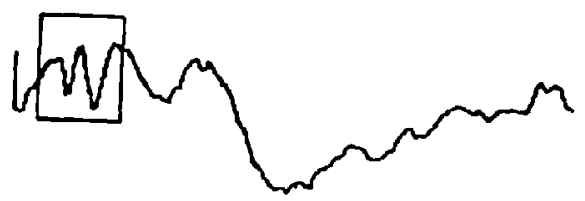

FigURE 1 Normal somatosensory evoked potential produced by stimulation of posterior tibial nerve during anaesthesia. Post-stimulus peak latencies and peak-to-peak amplitudes of the enclosed $W$-shaped complex are monitored during operation. Later components of the waveform are so variable that we do not find them useful for monitoring.

SCEP were recorded before anaesthesia, during anaesthesia but before hypotension, during actual or sham hypotension but before distraction of the spine, after distraction of the spine, and after reversal hypotension during closure of the wound. Waveforms were assessed visually in the operating room, using hand measurements and superimposition of paper records. Subsequently, post-stimulus latencies and peak-topeak amplitudes of individual peaks in the elicited waveforms were measured precisely using a controllable cursor on the monitoring system computer. Only the early cortical activity highlighted in Figure 1 was considered, because later components of the SCEP were excessively variable.

Patients came to the operating room for baseline recording 60 to 90 minutes before 
anaesthesia, but there were no delays for SCEP monitoring during operation. We were able to record throughout all phases of the surgical procedure except during use of the electrosurgical machine. SCEP recorded after distraction of the spine were compared with those recorded just before this manipulation. Increases in the post-stimulus latencies of individual peaks in waveforms, decreases in peak-to-peak amplitudes, and loss of definition in SCEP patterns were evaluated by subjective pattern recognition, hand measurements and superimposition of sequential records. Amplitude decreases of fifty per cent or more were invariably considered alarming, as were latency increases of four milliseconds or more from anaesthesia steadystate baselines. Smaller latency changes were alarming when amplitudes fell and pattern resolution deteriorated. When disturbing SCEP changes persisted more than 15 minutes, we reversed hypotension (if present) and haemodilution. If SCEP changes were not resolved by these measures, a wake-up test was done.

\section{Wake-up Test}

When SCEP changes failed to resolve after reversal of haemodilution and hypotension, we awakened patients and asked them to move both feet. First we determined the degree of neuromuscular blockade using an ulnar nerve stimulator. Small amounts of atropine and prostigmine were administered if necessary to produce a twitch similar to that seen before administration of pancuronium. We then discontinued nitrous oxide and ventilated the patient with oxygen at a flow exceeding minute ventilation. After two minutes the operation was suspended and the anaesthetist began talking to the patient, offering reassurance and asking the patient to move one hand. Only when hand movement was present in response to command did we assess voluntary motor function in the lower extremities, looking for strong symmetrical motion of both feet in response to verbal instructions. Anaesthesia was then resumed with thiopentone, nitrous oxide and pancuronium. Ventilation was controlled throughout to minimize the possibility of air embolism. For inadequate movement of feet, toes or ankles, we would have reduced distraction of the spine or removed Harrington instrumentation and would have repeated the wake-up test.

\section{Postoperative Neurological Assessment}

Sensory and motor function were assessed hourly for twenty-four hours after operation, then twice daily until patients left the hospital.

\section{RESUlts}

Thirteen patients were assigned to Group I (hypotension), eleven to Group II (sham hypotension). Ten patients hypotensive from decortication of bone to wound closure constituted Group IA; the three patients who had hypotension reversed made up Group IB. Groups I and II did not differ with respect to age, weight, preoperative haematocrit or baseline arterial blood pressure (Table I). Groups IA and II were similar with regard to number of vertebrae fused, lowest temperature during operation, lowest haematocrit during operation, volume of crystalloid infused and urine output (Table III). Nitroprusside alone was sufficient to keep systolic arterial blood pressure between 80 and 90 torr $(10.6$ to $12 \mathrm{kPa})$ in only four of thirteen cases. Propranolol was added in three cases, trimethaphan in four, both propranolol and trimethaphan in two.

\section{Arterial Blood Pressure}

Mean arterial blood pressures averaged 24 per cent below baseline during induced hypotension, nine per cent above baseline during sham hypotension. Corresponding systolic pressures were 16 per cent below and 19 per cent above baseline values (Table IV).

\section{Blood Loss}

Blood loss was almost twice as great in nonhypotensive patients (Group II) as in patients hypotensive throughout the operation (Group IA). This observation held when estimated blood loss was adjusted for total operating time, for number of vertebrae fused or for number of vertebrae fused and body weight (Table V). Though actual arterial blood pressure seemed more closely related to blood loss than did pressure represented as percentage of baseline, and systolic pressure seemed more closely related to blood loss than did mean pressure, correlations between blood loss and arterial pressure were so low as to be of uncertain clinical significance (Table VI). Hypotensive and non-hypotensive patients received similar volumes of blood in the operating room, but total transfusion on the day of operation was greater for non-hypotensive patients (Table V). Patients who had hypotension and haemodilution reversed received more blood, but since there were only three patients in this group we did not 
TABLE III

Characteristics of Patient Groups During Operation

\begin{tabular}{lcccccc}
\hline \hline & $\begin{array}{c}\text { Groupe IA } \\
\text { (Hypotension } \\
\text { Throughout) }\end{array}$ & $\begin{array}{c}\text { Group IB } \\
\text { (Hypotension } \\
\text { Reversed) }\end{array}$ & $\begin{array}{c}\text { Group II } \\
\text { (Sham } \\
\text { Hypotension) }\end{array}$ & p $^{*}$ \\
\hline Number of vertebrae fused & $10.3 \pm 2.2$ & $10.3 \pm 1.5$ & $10.8 \pm$ & 2.3 & NS \\
Lowest temperature ( ${ }^{\circ} \mathrm{C}$ ) & $35.0 \pm 1.0$ & $35.1 \pm 0.1$ & $35.3 \pm$ & 0.07 & $\mathrm{NS}$ \\
Lowest haematocrit (\%) & $30.4 \pm 1.8$ & $30.7 \pm 2.5$ & $29.5 \pm$ & \pm .0 & $\mathrm{NS}$ \\
Cystalloids given (ml) & $2309 \pm 358$ & $2178 \pm 286$ & 2021 & \pm 418 & $\mathrm{NS}$ \\
Urine Oupul (ml) & $319 \pm 171$ & $322 \pm 96$ & 457 & \pm 305 & $\mathrm{NS}$ \\
\hline
\end{tabular}

All values are given as mean \pm standard deviation.

"Group IA vs. Group II, Student's t test for unpaired data.

$\nmid \mathrm{NS}=$ Not significant at .05 level.

TABLE IV

arterial Pressure During Hypotension or Sham Hypotension

\begin{tabular}{|c|c|c|c|c|}
\hline & $\begin{array}{c}\text { Group IA } \\
\text { (Hypotension } \\
\text { Throughout) }\end{array}$ & $\begin{array}{c}\text { Group IB } \\
\text { (Hypotension } \\
\text { Reversed) }\end{array}$ & $\begin{array}{c}\text { Group II } \\
\text { (Sham } \\
\text { Hypotension) }\end{array}$ & $\mathbf{P}$ \\
\hline $\begin{array}{l}\text { Mean arterial pressure } \\
\text { actual (torr)* } \\
\text { as \% baseline* }\end{array}$ & $\begin{array}{l}60 \pm 4.6 \\
76 \pm 7.2\end{array}$ & $\begin{array}{l}72 \pm 13.6 \\
89 \pm 21.0\end{array}$ & $\begin{array}{r}91 \pm 14.3 \\
109 \pm 21.5\end{array}$ & $\begin{array}{l}<0.001 \dagger \\
<0.001 \dagger\end{array}$ \\
\hline $\begin{array}{l}\text { Systolic pressure } \\
\text { Actual (torr)* } \\
\text { as \% basline* }\end{array}$ & $\begin{array}{l}89 \pm 3.5 \\
84 \pm 9.8\end{array}$ & $\begin{array}{r}105 \pm 10.4 \\
99 \pm 12.8\end{array}$ & $\begin{array}{l}133 \pm 21.8 \\
119 \pm 21.5\end{array}$ & $\begin{array}{l}<0.001 \dagger \\
<0.001 \dagger\end{array}$ \\
\hline $\begin{array}{l}\text { Frequency with which } \\
\text { surgeon correctly } \\
\text { distinguished between } \\
\text { hypotension and sham } \\
\text { hypotension }\end{array}$ & $9 / 10$ & $20-12.0$ & $8 / 11$ & $<0.001 \mp$ \\
\hline
\end{tabular}

test for statistical significance. Haematocrits on the first postoperative day were similar for all groups.

\section{Surgeon's Assessment}

The surgeon recognized induced hypotension in twelve of thirteen patients; but he thought, incorrectly, that three of the eleven nonhypotensive patients had induced hypotension (Table IV). He correctly identified all three patients who had hypotension reversed. The surgeon tended to overestimate blood loss in the hypotensive group and underestimate loss in the non-hypotensive group.

\section{Operating Time}

Total operating times were shortest for non-hypotensive patients, but when operating times were corrected for the number of vertebrae fused and the number of rods inserted there was no significant difference in operating times between groups (Table V). Adjusted operating times for the five patients requiring wake-up tests did not differ significantly from operating times for those nineteen patients who did not require wake-up tests (Table VII).

\section{Spinal Cord Function}

None of our patients had obliteration of somatosensory cortical evoked potentials (SCEP) during operation. Five patients had SCEP changes after distraction of the spine that we considered suspicious. Three of these patients were in the hypotensive group, two in the non-hypotensive group. None of the SCEP changes resolved to our satisfaction with reversal of hypotension (if present) and haemodilution, so wake-up tests were done in all five patients. All wake-up tests showed satisfactory motor function in both lower extremities, and SCEP changes resolved satisfactorily before completion of the operation 
TABLE $V$

Blood Loss, Transfusion and Operating Time

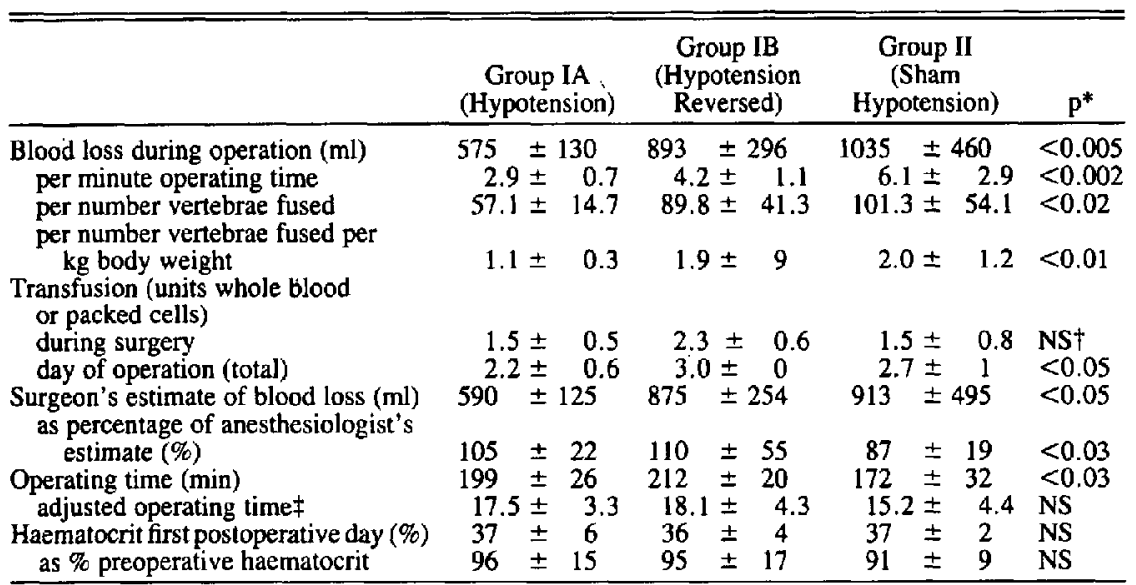

All values are given as mean \pm standard deviation.

*Group IA vs. Group II, Student's $t$ test for unpaired data.

† Not significant at 05 level.

†Minutes skin-to-skin $\div$ (number of vertebrae fused + number of rods inserted).

TABLE VI

Relationship Between Blood Loss During Operation and ARTERIAL BLOOD PRESSURE

\begin{tabular}{lcrrr}
\hline & $\begin{array}{c}\text { Correlation with } \\
\text { Corrected blood loss } \\
\text { during operation. } \\
\text { Pearson's Correlation } \\
\text { Coefficient }\end{array}$ & Y Intercept & Slope & p \\
\hline $\begin{array}{l}\text { Systolic pressure } \\
\text { actual }\end{array}$ & 0.503 & -14.6 & 0.862 & 0.006 \\
$\begin{array}{l}\text { as \% baseline } \\
\text { Mean pressure }\end{array}$ & 0.357 & 8.3 & 0.676 & 0.043 \\
actual & 0.425 & 4.2 & 1.023 & 0.019 \\
as \% baseline & 0.296 & 28.0 & 0.578 & 0.08 \\
\hline
\end{tabular}

Arterial pressures used were averages of pressures obtained at five minute intervals from start of bone decortication to beginning of wound closure. Corrected blood loss during operation was estimated loss (see text) divided by the number of vertebrae fused.

TABLE VII

WAKE-UP TESTS

\begin{tabular}{|c|c|c|c|c|c|}
\hline & \multicolumn{2}{|c|}{ Wake-up Test } & \multicolumn{2}{|c|}{ No Wake-up Test } & \multirow[b]{2}{*}{$\mathrm{p}^{*}$} \\
\hline & $\begin{array}{c}\text { Group I } \\
\text { (Hypotension } \\
\text { Reversed) }\end{array}$ & $\begin{array}{c}\text { Group II } \\
\text { (Sham } \\
\text { Hypotension) }\end{array}$ & $\begin{array}{c}\text { Group I } \\
\text { (Hypotension) }\end{array}$ & $\begin{array}{c}\text { Group I } \\
\text { (Sham } \\
\text { Hypotension) }\end{array}$ & \\
\hline $\begin{array}{l}\text { Number of patients } \\
\text { Adjusted operating time }\end{array}$ & $17.3 \pm 3.0$ & $16.7^{2} \pm 3.8$ & $\begin{array}{c}10 \\
15.2 \pm 5.8\end{array}$ & $15.2^{9} \pm 5.8$ & NS $\neq$ \\
\hline
\end{tabular}

*Wake-up vs. no wake-up, Student's t test for unpaired data.

†Minutes to skin $\div$ (\# vertebrae fused $+\not \#$ rods inserted); mean \pm standard deviation.

†Not significant at .05 level. 


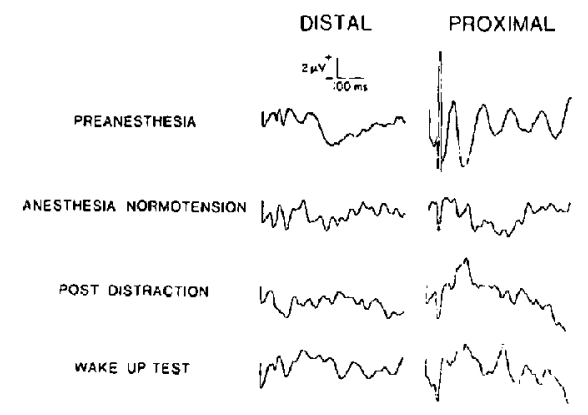

FIGURE 2 Representative SCEP changes during operation. Note the W-shaped complex highlighted in Figure 1; it is altered but not abolished by anaesthesia. "Distal" refers to potentials evoked by stimulation of the posterior tibial nerve at the ankle, "proximal" to potentials evoked by stimulation of the median nerve at the wrist. Distortion of this complex after distraction (straightening) of the spine prompted us to do a wake-up test. The wake-up test was normal and SCEP changes resolved satisfactorily before the end of operation.

in every patient. Representative waveform changes are shown in Figure 2. Neither reduction in distracting force nor removal of instrumentation was necessary in any case. All patients had normal spinal cord function postoperatively.

\section{Discussion}

Purported benefits of induced hypotension during orthopedic operations include reduction in blood loss, reduced need for transfusion, improved operating conditions and shorter operating times. ${ }^{4-6,18-20}$ These benefits must be weighed against the risks incurred when arterial pressure is lowered. Both benefits and risks vary with operative procedures and with patient characteristics. Risks accepted for difficult and dangerous operations (e.g., clipping of intracranial aneurysms ${ }^{21}$ ) may seem less justifiable for surgical procedures that can be safely accomplished without hypotension. ${ }^{22}$

Examining pooled series, Lindop ${ }^{23}$ found 2.6 per cent morbidity and 0.6 per cent mortality after induced hypotension during anaesthesia and operation. He concluded that risks were increased by preoperative hypertension or cerebrovascular disease; by hypocarbia, anaemia, rapid falls in arterial pressure, or mean arterial pressures less than seventy torr; by falls in cardiac output produced by hypovolaemia or cardiac depressant drugs; and by indifferent monitoring techniques. Even vigilant observation of accurately measured arterial pressure may not offer sufficient protection for all patients, however. Pressures safe for one individual may not be safe for another. ${ }^{24,25}$ Complications of deliberate hypotension may be minimized by monitoring organs at particular risk. $5,6,23,26$

MacEwen, ${ }^{1}$ in 1975, reported eighty-seven acute neurological complications associated with operative treatment of scoliosis that were described by forty-six members of the Scoliosis Research Society. Thirteen surgeons reported large series without any neurological complications. Of the 7,885 patients reported by those physicians who supplied data on all patients treated, fifty-seven ( 0.72 per cent) had acute neurological complications. Thirteen patients suffered damage to cranial or peripheral nerves, and most of these recovered completely. The spinal cord was injured in seventy-four patients. (This number includes cases reported by surgeons who failed to supply data on all patients treated.) Paraplegia was partial in thirty-three cases and complete in forty-one. Twenty-two patients recovered completely, twenty-eight only partially. Twenty-four patients (32 per cent) had no recovery at all. The actual incidence of spinal cord damage associated with operative treatment of scoliosis may well be even higher than the 0.61 per cent we estimate from MacEwen's report.

MacEwen found that certain patient characteristics and operative procedures were associated with increased risk of neurological damage after spinal fusion: kyphosis, congenital scoliosis, severe scoliotic curvature, preoperative neurological deficit, preoperative skeletal traction, spinal osteotomy, and certain uses of Harrington instrumentation. Yet paraplegia also occurred in patients with uncomplicated idiopathic scoliosis who had no special risk factors and in patients having spinal fusion without Harrington instrumentation. Recovery was more likely when neurological deficits were only partial. Though prognosis was improved when Harrington rods were removed within three hours of diagnosis, only nine of the twelve patients whose rods were promptly removed made complete recoveries.

Ponte* reported six cases of transient paraplegia after fusion of the spine with costotransversectomy and Harrington instrumentation. In all six cases cord function was restored by raising low arterial blood pressures

*Ponte, A.B.: Postoperative paraplegia due to hypercorrection of scoliosis and drop of blood pressure (abs). J. Bone Joint Surg. 56A: 444, 1974. 
above normal levels or by removing Harrington rods. One of our patients, previously reported, ${ }^{15}$ had changes in evoked potentials during operation that were reproducibly related to alterations in arterial pressure.

Spinal cord function can be compromised by stretching or other mechanical distortion of the cord as well as by pressure on blood vessels or on the cord itself. Griffiths, ${ }^{27}$ measuring blood flow by hydrogen clearance and function with dorsal column evoked potentials, showed in dogs that cord compression can alter dorsal column conduction at perfusion pressures not yet affecting blood flow. The lower limit for autoregulation of cord blood flow in Griffith's study was the same whether perfusion pressure was reduced by compression alone or by a combination of compression and chemically induced hypotension (trimethaphan and nitroprusside), but conduction failure with cord compression occurred at higher perfusion pressures in hypotensive animals. Brodkey ${ }^{7}$ found in cats that evoked potential changes produced by hypovolaemic hypotension and direct pressure on the spinal cord were consistently associated with subsequent loss of motor function in the lower extremities. The risk of neurological injury produced by cord compression is clearly increased during hypotension.

This series of twenty-four patients cannot define the relative risks of spinal cord damage with and without induced hypotension during spinal fusion for scoliosis. Because neurological injury is rare, a very large number of cases would be required to reach conclusions about relative rates of paraplegia. Even if the risk of cord damage were doubled, more than 10,000 patients would have to be studied, half with and half without hypotension, to detect this difference with 95 per cent confidence (test of difference of proportions using the arcsine transformation, assuming 0.61 per cent paraplegia without hypotension and no monitoring of spinal cord function during operation*).

The risk of neurological damage related to induced hypotension during spinal fusion for scoliosis, whatever it may be, can seemingly be minimized by monitoring spinal cord function during operation. The "wake-up test" $8-10$ is inexpensive and requires no special equipment.

*Using methods and tables in Cohen ${ }^{28}$ : one-tailed test, $\mathrm{p}<.05$; power $=.95$, effect size $\mathrm{h}=2$ arcsine $\sqrt{.0122}-2$ arcsine $\sqrt{.0061}=.065, \mathrm{~N}=$ $\left(2164 / 100 \mathrm{~h}^{2}\right)=5123$. Total cases required $=10,246$.
It provides definite evidence of intact motor function (anterior spinal cord), while the most frequently used electrophysiological measurements reflect only sensory (primarily dorsal column) function. ${ }^{29}$ Testing of voluntary motor function can be done only intermittently and infrequently, however, and the wake-up test may present some risks of its own. The patient might injure himself, disconnect or dislodge life support or monitoring devices, or dislodge orthopedic instrumentation. Spontaneous inspiration could produce air embolism. Physical and emotional distress might produce subsequent psychiatric symptoms. ${ }^{30}$

Electrophysiological monitoring allows repeated assessment of impulse transmission through the cord without awakening the patient, but all available methods require equipment that is expensive and more or less complex. Furthermore, many factors other than compromised cord function can affect sensory evoked potentials. Temperature, ${ }^{31,32}$ arterial blood gases $^{33,34}$ and anaesthetic agents ${ }^{35-43}$ can alter elicited wave forms. These possibly confusing factors must be monitored and kept as constant as possible during critical monitoring periods. Short-latency potentials recorded over the spine inside $^{14}$ or outside ${ }^{44-46}$ the operating field are less affected by these factors than are the intermediate-latency cortical potentials were monitored. Recordings from within the operating field do not lend themselves to preoperative or postoperative measurement, however, and there may be some value in monitoring potentials that reflect cerebral as well as spinal cord function during induced hypotension. ${ }^{34}$

Dorsal column transmission and SCEP may be preserved in the presence of isolated ventral cord lesions; ${ }^{47}$ but traumatic myelopathy usually affects multiple tracts and, clinically, SCEP changes are sensitive of spinal cord injury. ${ }^{48-50}$

Experience with evoked potential monitoring during operation ${ }^{12,14,15}$ is still limited. We do not know how much evoked potential alteration portends neurological damage. Because the incidence of cord damage is low in patients having spinal fusion for scoliosis, observations of many patients will be required to determine the reliability with which stable evoked potentials during operation predict intact cord function postoperatively. Evidence from studies in animals ${ }^{7,51,52}$ and from patients with spinal cord injury ${ }^{48-50}$ strongly suggests that reliability will be high, and there is as yet no evidence to the contrary. 
Monitoring of evoked potentials during operation will become even more valuable when we have quantitative descriptions of those evoked potential changes that should prompt intervention by the surgeon or anaesthetist. Our findings suggest that evoked potentials are at present sufficiently sensitive as indicators of impaired spinal cord function that wake-up tests can be safely omitted when somatosensory evoked potentials are stable during spinal fusion.

We conclude that moderate hypotension, though it does not affect operating time, improves operating conditions and significantly reduces blood loss during spinal fusion for scoliosis. Because hypotension may increase the risk of paraplegia, spinal cord function should be monitored when hypotension is employed as an adjunct to anaesthesia for operative treatment of scoliosis.

\section{REFERENCES}

1. MacEwen, G.D., Bunnell, W.P. \& SRIRam, K. Acute neurological complications in the treatment of scoliosis: A report of the Scoliosis Research Society. J. Bone Joint Surg. 57A: 404 (1975).

2. Moe, J.H., Winter, R.B., BradFord, D.S. \& LONSTEIN, J.E. Scoliosis and Other Spinal Deformities, 1st ed. Philadelphia: Saunders (1978).

3. WINTER, R.B. Treatment of scoliosis and possible neurologic complications, Spinal Deformities and Neurological Dysfunction. Edited by Chou, S.N., Seljeskog EL, 1st ed. New York, Raven Press, 1978, pp 209.

4. Goldstein, L.A. Surgical management of scoliosis. J. Bone Joint Surg. 48A: 167 (1966).

5. MoNeill, T.W., DeWald, R.L., Kuo, K.N., BENNETT, E.J. \& SALEM, M.R. Controlled hypotensive anesthesia in scoliosis surgery. $J$. Bone Joint Surg 56A: 1167 (1974).

6. Khambatta, H.J., Stone, J.G., Matteo, R.S. \& MiChELSEN, W.J. Hypotensive anesthesia for spinal fusion with sodium nitroprusside. Spine 3 : 171 (1978).

7. Brodkey, J.S., Richards, D.E., Blasingame, J.P. \& NuLSEN, F.E. Reversible spinal cord trauma in cats: Additive effects of direct pressure and ischemia. J. Neurosurg. 37: 591 (1972).

8. Vauzelle, C., Stagnara, P. \& Jouvinroux, P. Functional monitoring of spinal cord activity during spinal surgery. Clin. Orthop. 93: 173 (1973).

9. SUdhIR, K.G., SMITH, R.M., HALl, J.E. \& HANSEN, D.D. Intraoperative awakening for early recognition of possible neurologic sequelae during Harrington-rod spinal fusion. Anesth. Analg. (Cleve) 55: 526 (1976).

10. Hall, J.E., Levine, C.R. \& SudhiR, K.G. Intraoperative awakening to monitor spinal cord function during Harrington instrumentation and spine fusion: Description of procedure and report of three cases. J. Bone Joint Surg. 60A: 533 (1978).

11. STARR, A. Sensory evoked potentials in clinical disorders of the nervous system. Ann. Rev. Neurosci. 1: 103 (1978).

12. Nash, C.L., LoRIG, R.A., Schatzinger, L.A. \& BRowN, R.H. Spinal cord monitoring during operative treatment of the spine. Clin. Orthop. 126: 100 (1977).

13. Engler, G.L., Spielholz, N.I., Bernhard, W.N., DANZIGER, F., MERKIN, H. \& WOLFF, T. Somatosensory evoked potentials during Harrington instrumentation for scoliosis. J. Bone Joint Surg. 60A: 528 (1978).

14. Nordwall, A., Axelgaard, J., Harada, Y., VALENCIA, P., MCNEAL, D.R. \& BROWN, J.D. Spinal cord monitoring using evoked potentials recorded from feline vertebral bone. Spine 4: 486 (1979).

15. Grundy, B.L., Nash, C.L. \& Brown, R.H. Arterial pressure manipulation alters spinal cord function during correction of scoliosis. Anesthesiology 54: 249 (1981).

16. Relton, J.E.S. \& Hall, J.E. An operation frame for spinal fusion: A new apparatus designed to reduce haemorrhage during operation. Br. J. Bone Joint Surg. 49B: 327 (1967).

17. JASPER, H.H. The ten twenty electrode system of the International Federation. Electroencephalogr. Clin. Neurophysiol. 10: 371 (1958).

18. Thompson, G.E., Miller, R.D., Stevens, W.C. \& MURRAY, W.R. Hypotensive anesthesia for total hip arthroplasty: A study of blood loss and organ function (brain, heart, liver, and kidney). Anesthesiology 48: 91 (1978).

19. Amaranath, L., Cascorbi, H.F., Singhamaranath, A.V. \& Frankmann, D.B. Relation of anesthesia to total hip replacement and control of operative blood loss. Anesth. Analg. (Cleve) 54: 641 (1975).

20. VAZEERY, A.K. \& LUNDE, O. Controlled hypotension in hip joint surgery: An assessment of surgical haemorrhage during sodium nitroprusside infusion. Acta. Orthop. Scand. 50:433 (1979).

21. Yashon, D., Magness, A.P. \& Vise, W.M. Systemic hypotension in neurosurgery. $J$. Neurosurg. 43: 579 (1975).

22. SaFAR, P. A study of deliberate hypotension in anesthesia, with special consideration of surgical blood loss in comparable groups of normotensive and hypotensive anesthesia. Surgery 37: 1002 (1955).

23. LINDOP, M.J. Complications and morbidity of controlled hypotension. Br. J. Anaesth. 47: 799 (1975).

24. WARNER, W.A., SHumrick, D.A. \& CaFFreY, J.A. Clinical investigation of prolonged induced hypotension in head and neck surgery. $\mathrm{Br} . \mathrm{J}$. Anaesth. 42: 39 (1970).

25. Prys-Roberts, C., Lloyd, J.W., Fisher, A., KerR, H. \& Patterson, T.J.S. Deliberate profound hypotension induced with halothane: Studies of haemodynamics and pulmonary gas exchange. Br. J. Anaesth. 46: 105 (1974).

26. PrIOR, P.F. Monitoring Cerebral Function: 
Long-term Recordings of Cerebral Electrical Activity, 1st ed. Amsterdam: Elsevier/NorthHolland Biomedical Press (1979).

27. GRIFFThS, I.R., TRENCH, J.G. \& CRawFord, R.A. Spinal cord blood flow and conduction during experimental cord compression in normotensive and hypotensive dogs. J. Neurosurg. 50: 353 (1979).

28. Cohen, J. Statistical Power Analyses for the Behavioral Sciences, 1st ed. New York Academic Press (1969) pp 199

29. Cusick, J.F., Myklebust, J.B., Larson, S.J. \& SANCES, A. JR. Spinal cord evaluation by cortical evoked responses. Arch. Neurol. 36: 140 (1979).

30. BLACHER, R.A. On awakening paralyzed during surgery: A syndrome of traumatic neurosis. JAMA 234: 67 (1975).

31. AUNON, J.I., Weirich, W.E. \& NyHOLM, R. Effects of hypothermia on the visual-evoked brain potential in dogs. Am. J. Vet. Res. 38: 383 (1977).

32. Stockard, J.J., Sharbrough, F.W. \& Tinker, J.A. Effects of hypothermia on the human brainstem auditory response. Ann. Neurol. 3: 368 (1978)

33. GRIFFITHS, I.R. Spinal cord blood flow in dogs: 2. The effect of the blood gases. J. Neurol. Neurosurg. Psychiat. 36: 42 (1973)

34. Grundy, B.L., Heros, R.C., Tung, A.S. \& DOYLE, E. Intraoperative hypoxia detected by evoked potential monitoring. Anesth. Analg. (Cleve) 60:437 (1981)

35. Amrahamian, H.A., Allison, T., Goff, W.R. \& ROSNER, B.S. Effects of thiopental on human cerebral evoked responses. Anesthesiology 24: $650(1963)$

36. CoRssen, G. \& Domino, E.F. Visually evoked responses in man: A method for measuring cerebral effects of preanesthetic medication. Anesthesiology 25: 330 (1964).

37. DOMINO E.F. Effects of preanesthetic and anesthetic drugs on visually evoked responses. Anesthesiology 28: 184 (1967)

38. Clark, D.L. \& RosNer, B.S. Neurophysiologic effects of general anesthetics: I: The electroencephalogram and sensory evoked responses in man. Anesthesiology 38: 564 (1973).

39. GRUNDY, B.L., Brown, R.H. \& Greenberg P.S. Diazepam alters cortical evoked potentials (abs.). Anesthesiology 51: S38 (1979).

40. Grundy, B.L., Brown, R.H. \& Clifton, P.C.
Effect of droperidol on somatosensory cortical evoked potentials (abs.). Electroencephalogr. Clin. Neurophysiol. 50: 158P (1980).

41. Grundy, B.L., Brown, R.H. \& Berilla, J.A. Fentanyl alters somatosensory cortical evoked potentials (abs.). Anesth. Analg. (Cleve) 59:544 (1980).

42. Grundy, B.L. \& Brown, R.H. Meperidine enhances somatosensory cortical evoked potentials. Electroencephalogr. Clin. Neurophysiol. 50: $177 \mathrm{P}$ (1980)

43. Uhl, R.R., Squires, K.C., Bruce, D.L. \& STARR, A. Effect of halothane anesthesia on the human cortical visual evoked response. Anesthesiology 53: 273 (1980).

44. Cracco, R.Q., \& Cracco, J.B. Somatosensory evoked potential in man: Far field potentials. Electroencephalogr. Clin. Neurophysiol. 41:460 (1976).

45. Sances, A., Larson, S.J., Cusick, J.F., MYKleBust, J., EWING, C.L., JODAT, R., ACKMANN, J.J. \& WALSH, P. Early somatosensory evoked potentials. Electroencephalog. Clin. Neurophysiol. 45: 505 (1978).

46. ChiapPa, K.H., Choi, S. \& Young, R.R. Short latency somatosensory evoked potentials following median nerve stimulation in patients with neurological lesions. Prog. Clin. Neurophysiol. 7: 264 (1980).

47. Halliday, A.M. \& Wakefield, G.S. Cerebral evoked potentials in patients with dissociated sensory loss. J. Neurol. Neurosurg. Psychiat. 26: 211 (1963)

48. Perot, P.L. The clinical use of somatosensory evoked potentials in spinal cord injury. Clin. Neurosurg. 20:367 (1972).

49. Rowed, D.W., McLean, J.A. \& TatoR, C.H. Somatosensory evoked potentials in acute spinal cord injury: Prognostic value. Surg. Neurol. 9: 203 (1978).

50. Larson, S.J., Holst, R.A., Hemmy, D.C. \& SANCES, A. JR. Lateral extracavitary approach to traumatic lesions of the thoracic and lumbar spine. J. Neurosurg. 45: 628 (1976).

51. MARTIN, S.H. \& BlOEDEL, J.R. Evaluation of experimental spinal cord injury using cortical evoked potentials. J. Neurosurg. 39: 75 (1973).

52. D'ANGELO, C.M., VANGILDER, J.C. \& TAUB, A. Evoked cortical potentials in experimental spinal cord trauma. J. Neurosurg. 38: 332 (1973).

\section{RESUME}

L'emploi d'une hypotension contrôlée modérée (maintien de la pression systolique entre 80 et 90 torr) au cours de fusions vertébrales par tige de Harrington a été étudié de façon prospective. Les paramètres étudiés étant le volume des pertes sanguines opératoires, la qualité du champ opératoire, la durée de l'intervention et le maintien de la fonction medullaire. Les vingt quatre patients inclus dans cette étude étaient assignés au hasard au groupe témoin ou au groupe opéré sous hypotension contrôlée.

Nous avons observé des pertes sanguines moindres ainsi qu'une qualité supérieure du champ opératoire chez les patients operés sous hypotension contrôlée. La durée de l'intervention n'était cependant pas raccourcie. Cinq des patients ont présenté des 
modifications des potentiels corticaux induits par stimulation somato-sensorielle; dans ces cas la pression était ramenée à la normale lorsque l'hypotension contrôlée était utilisée, l'hémodilution était corrigée et le malade était éveillé en cours de chirurgie pour vérifier si la motricité volontaire des membres inférieurs était conservé. Tous les tests d'éveil se sont avérés normaux et les potentiels corticaux évoqués se sont corrigés en cours d'intervention. L'emploi d'hypotension contrôlée ne semble pas susceptible d'augmenter le risque de dommages neurologiques si le maintien de la fonction de la moelle épinière est surveillé en cours de chirurgie.

Nos résultats suggèrent que les malades soumis à une fusion vertébrale n'ont pas à être éveillés en cours d'intervention pour vérification du maintien de leur fonction medullaire en autant que l'on effectue le monitoring per-opératoire des potentiels corticaux induits par stimuli corticaux sensoriels et que cette fonction est maintenue stable. 